\title{
PERANCANGAN DAN OPTIMASI SISTEM PEMBANGKIT LISTRIK MIKROHIDRO DENGAN DAYA 8.5 KW
}

\author{
Rusuminto ${ }^{1}$, Wibowo Paryatmo \\ 1) Pengajar di Jurusan Mesin Otomotif Politeknik Negeri Tanah Laut
}

\begin{abstract}
Intisari- Penelitian ini membahas mengenai perancangan dan optimalisasi turbin air dengan memanfaatkan sumber energi air yang mempunyai ketinggian kotor 18 meter dengan beda ketinggian 12,1 meter, sungai tiwingan mempunyai debit 0,33 meter kubik perdetik dengan potensi daya listrik 8,5 Kw. Dari analisa yang didapat diperoleh jenis turbin yang sesuai adalah jenis turbin Crossflow, dipilihnya jenis turbin tersebut dikarenakan ketersedian teknologi secara lokal dan biaya pembuatan yang lebih murah metode yang dipakai adalah menganalisa segitiga kecepatan pada bagian runner turbin dengan memvariasikan sudut alfa, dari sudut alfa 7 derajat sampai dengan 16 derajat dengan mengambil sudut aliran alfa 14 derajat sebagai contoh rancangan. Hasil yang diperoleh dari pengambilan contoh sudut aliran 14 derajat adalah 89.457 $\mathrm{Kw}$
\end{abstract}

Kata kunci- energi mikrohidro, turbin, cross flow.

\section{PENDAHULUAN}

Kawasan waduk PLTA IR.P.H.M.NOOR memiliki 8 aliran sungai yang dikumpulkan dalam sebuah dam, salah satu sungai tersebut adalah sungai tiwingan yang mempunyai beda ketinggian 18 meter, beda ketinggian tersebut besar sekali potensinya untuk dibangun beberapa buah sistem pembangkit listrik skala mikro sungai tiwingan merupakan sungai yang sumber airnya berasal dari hulu pegunungan meratus, letak waduk PLTA Riam Kanan berada didaerah gunung, topografi tersebut yang bergunung-gunung memungkinkan sungai yang ada didaerah tersebut bisa dimanfaatkan untuk mengembangkan PLTMH.

Pengembangan energi mikrohidro sangat cocok dilakukan mengingat potensi yang ada mempunyai debit kemarau diperkirakan $0,33 \mathrm{~m} 3 / \mathrm{s}$ dengan potensi ketinggian lebih dari 12,1 m.

Berdasarkan deskripsi di atas maka penelitian ini merumuskan per masalahan antara lain :

1. Seberapa besar potensi dari sumber energi yang ada yang dapat dimanfaatkan.

2. Bagaimana mendesain rancangan PLTMH beserta optimasi desainnya dengan potensi yang ada.

Berdasarkan potensi dan permasalahan tersebut, maka akan dibahas mengenai:

1. Merencanakan dan Mendesain PLTMH sesuai dengan potensi sumber energi air yang terdapat disungai tiwingan di desa awang bangkal.

2. Mengoptimasi desain rancangan sistem PLTMH untuk sungai tiwingan sehingga daya listrik yang akan dibangkitkan dapat diketahui dengan penentuan sudut $\alpha$.

Rencana desain sistem pada PLTMH sungai tiwingan dilakukan pada bagian penstock dan runner turbin, sehingga ruang lingkup penelitiannya meliputi:

1. Besaran debit aliran sungai yang diambil dalam perhitungan rencana perancangan teknis adalah debit minimum pada musim kemarau yaitu $0.33 \mathrm{~m}^{\wedge} 3 / \mathrm{s}$.

2. $\quad$ Ketinggian $(\mathrm{z})=12,1 \mathrm{~m}$

3. Turbin yang dipakai adalah cross flow.

4. Rencana desain rancangan dengan mempelajari segitiga kecepatan dengan variasi sudut $\alpha 70$ - 160 .

5. Perhitungan pada penstock adalah:

a. Diameter pipa

b. Kecepatan air pada pipa

6. Bagian-bagian pendukung PLTMH meliputi rancangan sipil dan kelistrikan tidak diperhitungkan.

7. Studi kelayakan mempertimbangkan kemandirian listrik serta biaya penghematan listrik yang didapat dengan di bangunnya PLTMH didaerah tersebut.

\section{METODE}

Penelitian ini akan dilaksanakan dengan langkah sebagai berikut :

a. Diawali peninjauan lokasi, dengan cara menelusuri aliran sungai, menentukan titik yang dianggap sesuai untuk perencanaan PLTMH.

b. Pengambilan data-data :

- Primer:

- Menghitung secara langsung debit aliran menggunakan alat ukur debit:

- Menggunakan beda ketinggian air pada tabung pitot yang mana beda ketinggiannya $29 \mathrm{~cm}$.

- Menggunakan benda apung berupa kayu meranti ukuran $10 \times 10 \mathrm{~cm}$ yang dijatuhkan kepermukaan air sungai kemudian kecepatannya di ukur dengan menggunakan stopwatch dalam jarak $5 \mathrm{~m}$.

- Mengukur beda ketinggian yang berpotensi untuk mendapatkan head maksimal, dengan menggunakan water pas dari selang kecil Sekunder : 
- Pengambilan informasi data tingkat curah hujan dibadan klimatologi dan geofisika Banjarmasin.

- Melakukan perhitungan data kasar sementara untuk mengetahui rencana desain potensi daya listrik terbangkit.

- Mengevaluasi data pengukuran dan hasil perhitungan

- Mengoptimasi desain rancangan sistem PLTMH

\section{Parameter-Parameter Rancangan PLTMH}

a. Penentuan debit aliran

Pengukuran debit dengan menggunakan pendekatan: $Q=V \cdot A$

Dimana $\quad V=$ kecepatan aliran $=2.38 \mathrm{~m} / \mathrm{s}$

$A=$ Luas penampang aliran $=0.14 \mathrm{~m}^{2}$

Jadi diperoleh debit aliran $0.33 \mathrm{~m} 3 / \mathrm{s}$ atau 340.01052 liter/sekon

b. Penentuan ketinggian optimum

Dari data pengukuran dilapangan diperoleh ketinggian efektif $=12.1 \mathrm{~m}$

c. Pemilihan Turbin

Berdasarkan data debit dan beda ketinggian perhitungan potensi daya minimum, maka tipe turbin direncanakan tipe Turbin cross flow.

d. Efisiensi Turbin dan Generator

Untuk Turbin crossflow $\eta_{\mathrm{t}}=0.6$ pada debit $40 \%$ baik sampai 0.74

Efisiensi generator untuk aplikasi 50 - 100 kVA efisiensi 0.85 - 0.9

e. Potensi Daya listrik yang ada

Dari data yang didapat, saluran ini memiliki debit minimum $(\mathrm{Q})=0.33 \frac{\mathrm{m}^{\mathrm{s}}}{\mathrm{s}}$ namun sebenarnya dapat dioptimasikan untuk dinaikkan debitnya dengan membuat bendungan, sedangkan untuk ketinggian $\operatorname{pipa}(\mathrm{z})=12,1 \mathrm{~m}$, mempunyai daya sebesar :

$$
\begin{aligned}
& P=\rho Q g z \eta_{0} \\
& \quad=1000 \frac{\mathrm{kg}}{\mathrm{m}^{3}} \cdot 0.33 \frac{\mathrm{m}^{3}}{\mathrm{~s}} \cdot 9.81 \frac{\mathrm{m}}{\mathrm{s}^{\mathbf{2}}} \cdot 9.6 \mathrm{~m} \cdot 0.6 \cdot 0.6 . \\
& 0.6 \\
& \quad=6712.8 \mathrm{~W}=6,7 \mathrm{~kW}
\end{aligned}
$$

Sedangkan untuk memaksimalkan efisiensi dapat dilakukan dengan menganalisa segitiga kecepatan pada runner turbinnya.

\section{KajianTekno ekonomi}

Tahap awal dalam melaksanakan suatu proyek diperhitungkan adalah perlunya dilakukan analisa dari investasi tersebut sehingga akan diketahui kelayakan suatu proyek dilihat dari sisi ekonomi investasi dan daya keluaran listrik yang dihasilkan dibandingkan harga listrik dari PLN.

\section{HASIL DAN PEMBAHASAN}

Penggunaan energi listrik untuk penerangan rumah di daerah awang bangkal kecamatan Aranio kabupaten Banjar dan kebutuhan yang lain bersumber dari PLTA IR.P.H.M.NOOR, padahal sungai tiwingan yang terdapat didesa tersebut mempunyai potensi untuk dikembangkan sistem pembangkit listrik skala kecil.

Pemanfaatan potensi sumber daya alam yang ada berupa air untuk PLTMH sangat baik dikarenakan sungai tiwingan memiliki beda ketinggian 18 meter, potensi ini baik untuk dimanfaatkan mengingat pasokan energi listrik diwilayah Kalimantan Selatan umumnya sering mengalami defisit daya apabila saat beban puncak, hal ini mengakibatkan terjadinya pemadaman listrik secara bergilir dalam mengatasi kesulitan tersebut di upayakan perancangan pembuatan PLTMH untuk memutuskan ketergantungan pasokan listrik kepada PLN mengingat lokasi yang terletak pada daerah pegunungan dan rumah yang saling berjauhan, sehingga perlu pengembangan potensi yang optimal untuk pembangkit listrik mandiri.

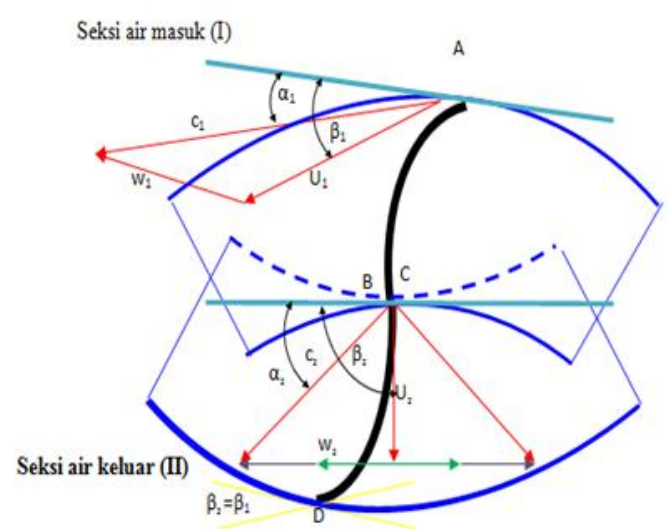

Gambar 1. segitiga kecepatan seksi air masuk sudu

Tabel 1. Data Desain Teknis

\begin{tabular}{|l|c|c|c|}
\hline \multicolumn{1}{|c|}{ Besaran } & Simbol & Satuan & Nilai \\
\hline Debit & $\mathrm{Q}$ & $\mathrm{m}^{3} / \mathrm{s}$ & 0,33 \\
\hline Ketinggian & $\mathrm{Z}$ & $\mathrm{m}$ & 12,1 \\
\hline Konstanta Kecepatan & $\mathrm{K}$ & & 0,087 \\
\hline Sudut masuk & $\mathrm{A}$ & $\left(^{0}\right)$ & 14 \\
\hline Koefisien empiris & $\mathrm{C}$ & & 0,98 \\
\hline Efisiensi Turbin & $\eta_{\mathrm{t}}$ & & 0,76 \\
\hline Massa Jenis air & $\mathrm{P}$ & $\mathrm{kg} / \mathrm{m}^{3}$ & 1000 \\
\hline Percepatan gravitasi & $\mathrm{G}$ & $\mathrm{m} / \mathrm{s}^{2}$ & 9,81 \\
\hline
\end{tabular}


Tabel 2. Hasil Analisis Perhitungan Segitiga Kecepatan Turbin

\begin{tabular}{|l|c|c|c|}
\hline \multicolumn{1}{|c|}{ Besaran } & Simbol & Satuan & Nilai \\
\hline Gaya & $\mathrm{F}$ & $\mathrm{N}$ & 12,09 \\
\hline Momen puntir / torsi & $\mathrm{T}$ & $\mathrm{Nm}$ & 5,75 \\
\hline Daya Turbin & $\mathrm{P}$ & $\mathrm{kW}$ & 89,46 \\
\hline
\end{tabular}

Tabel 3. Tabel Hasil Perhitungan Pipa Penstock (Penstock)

\begin{tabular}{|l|c|c|c|}
\hline \multicolumn{1}{|c|}{ Besaran } & Simbol & Satuan & Nilai \\
\hline Diameter dalam & $\mathrm{Di}$ & $\mathrm{m}$ & 0,45 \\
\hline Panjang & $\mathrm{Lp}$ & $\mathrm{m}$ & 18 \\
\hline Tinggi & $\mathrm{Hp}$ & $\mathrm{m}$ & 12,1 \\
\hline Kecepatan aliran & $\mathrm{V}$ & $\mathrm{m} / \mathrm{s}$ & 15,40 \\
\hline
\end{tabular}

Tabel 4 Hasil Perhitungan Dimensi Turbin

\begin{tabular}{|l|l|l|l|}
\hline Besaran & Simbol & Satuan & Nilai \\
\hline Putaran Turbin & $\mathrm{N}$ & $\mathrm{Rpm}$ & 300 \\
\hline Lebar & $\mathrm{L}$ & $\mathrm{m}$ & 1,40 \\
\hline Diameter runner & $\mathrm{D}_{1}$ & $\mathrm{~m}$ & 0,75 \\
\hline Jari-jari runner & $\mathrm{r}_{1}$ & $\mathrm{~m}$ & 0,375 \\
\hline Jari-jari runner & $\mathrm{r}_{2}$ & $\mathrm{~m}$ & 0,25 \\
\hline Kecepatan Spesifik & $\mathrm{n}_{\mathrm{s}}$ & $\mathrm{Rpm}$ & 170 \\
\hline Tebal Pancaran & $\mathrm{So}$ & $\mathrm{m}$ & 0,061 \\
\hline Jarak antar sudu & $\mathrm{T}$ & $\mathrm{m}$ & 0,1304 \\
\hline Jumlah sudu & $\mathrm{N}$ & $\mathrm{Buah}$ & 18 \\
\hline Lebar keliling radial & $\mathrm{A}$ & $\mathrm{m}$ & 0,1275 \\
\hline Diameter dalam & $\mathrm{Di}$ & $\mathrm{m}$ & 0,495 \\
\hline Kelengkungan Sudu & $\Delta$ & $\mathrm{m}$ & 0,375 \\
\hline Massa turbin total & $\mathrm{WT}_{\text {tot }}$ & $\mathrm{Kg}$ & 25,195 \\
\hline NOZEL & \multicolumn{5}{|l}{} \\
\hline $\begin{array}{l}\text { Kecepatan aliran } \\
\text { penstock bagian atas }\end{array}$ & $\mathrm{V}_{1}$ & $\mathrm{~m} / \mathrm{s}$ & 20,76 \\
\hline $\begin{array}{l}\text { Kecepatan aliran } \\
\text { penstock bagian } \\
\text { bawah }\end{array}$ & $\mathrm{V}_{2}$ & $\mathrm{~m} / \mathrm{s}$ & 15,1 \\
\hline $\begin{array}{l}\text { Luas penampang } \\
\text { keluar nosel }\end{array}$ & $\mathrm{A}$ & $\mathrm{m}^{2}$ & 1,26 \\
\hline $\begin{array}{l}\text { Lebar penampang } \\
\text { keluar nosel }\end{array}$ & $\mathrm{B}$ & $\mathrm{m}$ & 0,100 \\
\hline
\end{tabular}

\section{Analisa Perhitungan Ekonomi}

Pada tahap awal pembangunan PLTMH memerlukan investasi yang relatif besar. Namun bila ditinjau dengan hasil yang diperoleh dapat menghemat biaya listrik, disamping itu melihat kondisi medan/lapangan yang sulit untuk instalasi listrik dari PLN, bila dimungkinkan dilakukan instalasi biayanya sangatlah mahal dibandingkan dengan instalasi PLTMH, sehingga investasi PLTMH yang mahal menjadi murah. Biaya dalam rancangan PLTMH sungai tiwingan diperkirakan mencapai Rp.109 440 000,-. Adapun perincian biaya perancangan PLTMH tiwingan ada pada table dibawah ini:

Tabel 5. Hasil optimasi pada turbin dengan variasi sudut $\alpha 1$ yaitu $7^{0}-15^{0}$

\begin{tabular}{|c|c|c|c|c|c|c|c|c|c|c|c|}
\hline a & 7 & 8 & 9 & 10 & 11 & 12 & 13 & 14 & 15 & 16 & $\begin{array}{l}\text { Ratr } \\
\text { risto } \\
\end{array}$ \\
\hline $\cos \theta$ & 0.99254 & 0.99066 & 0.58768 & 0.9848 & 0.98162 & 0.97814 & 0.97437 & 0.97029 & 0.95592 & 0.56126 & 9.76688 \\
\hline$\beta_{1}=2 \tan a_{1}$ & 0.2455 & 0.28108 & 0.31676 & 0.35265 & 0.38876 & 0.42511 & 0.41736 & 0.49865 & 0.53589 & 0.57349 & 0.403525 \\
\hline$\beta_{1}$ & 14 & 16 & 18 & 20 & 21 & 23 & 25 & 27 & 29 & 30 & 22.3 \\
\hline $\cos \beta_{3}$ & 097 & 0.961 & 0.551 & 0.939 & 0.933 & 0.92 & 0.91 & 0.891 & 0.874 & 0.866 & 0.9215 \\
\hline C & 1068 & 1068 & 10.68 & 10.68 & 10.68 & 1068 & 10.68 & 10.68 & 1068 & 1068 & 10.68 \\
\hline 01 & 73966 & 7.996 & 7.396 & 7396 & 7.396 & 7.396 & 7.396 & 7.996 & 7.396 & 7.396 & 7.396 \\
\hline m1 & 1066033 & 10575988 & 105.5442 & 10551765 & 10.4837 & 10.4654 & 10.40627 & 103527 & 1031603 & 10.26626 & 10,45239 \\
\hline cu1 & 17.678 & 17.559 & 17427 & 17272 & 17.17 & 17.006 & 16.865 & 16.629 & 164.12 & 16.286 & 17.0312 \\
\hline & & & & & & & & & & & \\
\hline$c_{2}$ & -9.32 & .9 .32 & -9.32 & -9.32 & 9.932 & .9 .32 & -9.32 & -9.32 & .9 .32 & -9.32 & .9 .32 \\
\hline 02 & 7396 & 7.396 & 7.396 & 7936 & 7.396 & 7.396 & 7.396 & 7396 & 7.396 & 7.396 & 7.396 \\
\hline$m_{2}$ & 9.5402 & 9.5183 & 9,493 & 9.4588 & 9.4353 & 9.4018 & 9.3656 & 9.3264 & 9.2844 & 9.2396 & 9.4071 \\
\hline $\mathrm{CU2}$ & 7.396 & 7.996 & 7.396 & 7396 & 73966 & 7.396 & 7.396 & 7396 & 7.396 & 7.396 & 7.396 \\
\hline Setinger & & & & & & & & & & & \\
\hline f & 13.499 & 1331 & 13.141 & 12937 & 12813 & 12590 & 12.455 & 12055 & 11811 & 11.646 & 12.623 \\
\hline$t$ & 62622 & 6.2039 & 6.1390 & 6.0627 & 60.061 & 5.9324 & 5.8650 & 5.7468 & 5.6403 & 5.5785 & 5.944 \\
\hline$p$ & 9952291 & 98471.85 & 97193.28 & 956587.03 & 97788.61 & 93116.85 & 91749,72 & 894579 & 87355.86 & 866138.68 & 93356.27 \\
\hline
\end{tabular}

Tabel 6. Estimasi Biaya Pembuatan rancangan PLTMH tiwingan

\begin{tabular}{|c|c|c|c|c|}
\hline $\begin{array}{l}\mathrm{N} \\
\mathrm{O}\end{array}$ & $\begin{array}{l}\text { Keterang } \\
\text { an }\end{array}$ & Unit & $\mathrm{Jml}$ & $\begin{array}{l}\text { Total Harga } \\
(\mathrm{Rp})\end{array}$ \\
\hline 1 & $\begin{array}{l}\text { Peralatan } \\
\text { Pembang } \\
\text { kit }\end{array}$ & $\begin{array}{l}\text { Turbin, } \\
\text { generator } \\
\text {, set-up \& } \\
\text { komisi }\end{array}$ & 1 & $40000000,-$ \\
\hline 2 & $\begin{array}{l}\text { Pekerjaan } \\
\text { sipil }\end{array}$ & $\begin{array}{l}\text { Biaya } \\
\text { persiapan } \\
\text { pembuat } \\
\text { an } \\
\text { bendung } \\
\text { an power } \\
\text { house }\end{array}$ & & $25250000,-$ \\
\hline 3 & $\begin{array}{l}\text { Instalasi } \\
\text { Listrik }\end{array}$ & $\begin{array}{l}\text { Tiang, } \\
\text { kabel, } \\
\text { aksesoris } \\
\text {, instalasi }\end{array}$ & & $23140000,-$ \\
\hline 4 & $\begin{array}{l}\text { Biaya } \\
\text { Perawata } \\
\text { n / Tahun }\end{array}$ & & & $21050000,-$ \\
\hline \multicolumn{4}{|c|}{ Jumlah } & $109440000,-$ \\
\hline
\end{tabular}




\section{KESIMPULAN}

I. Dari data potensi yang ada diperoleh beda ketinggian $(\mathrm{z})=12,1$ pengukuran debit aliran mimimum pada sungai $(\mathrm{Q})=$ $0,33 \mathrm{~m} 3 / \mathrm{s}$, Diameter penstock $=0,30 \mathrm{~m}$ Efisiensi turbin, hidrolik dan generator masing-masing 0,6 Daya listrik yang dibangkitkan 8,5 kW.

Dari optimasi yang dilakukan yaitu perhitungan berbasis segitiga kecepatan diperoleh : Debit aliran $\mathrm{Q}=1,31 \mathrm{~m} 3 / \mathrm{s}$ Diameter penstock $=0,45 \mathrm{~m}$ Hconv $=65 \mathrm{~J} / \mathrm{kg}$ Hnet $=86,61$

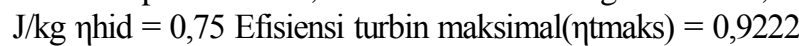
Daya listrik yang dibangkitkan pada sudut masuk runner $\alpha 1=70$ adalah $89,622 \mathrm{~kW}$

\section{UCAPAN TERIMA KASIH}

Penghargaan dan ucapan terimakasih kepada Istri dan anak tercinta, kedua orang tua, keluarga, dan kepada Prof. Dr. Ir. H. Djoko Sungkono K, M.Eng.Sc.

\section{DAFTAR PUSTAKA}

[1] Fritz Dietzel. Dakso Sriyono,1980 Turbin Pompa dan Kompresor.

[2] R.K Rajput, 2003. A Textbook of Hydraulic machines

[3] Paryatmo W. 2005. Turbin Air, Jakarta. UPP.

[4] Agus S. Karakteristik Turbin Cross Flow http://www.agussuwasono.com/artikel/mechanical/3 00-karakteristik-turbin-cross-flow.html?start=1 (03/01/2011)

[5] Ahmad Farid, , 2010 Optimasi Turbin Arus silang untuk PLTMH sungai Guci .Tesis S2 Universitas Pancasila.

[6] Barglazan M. 2005. About Design Opimization of Cross flow Hidraulic Turbines. Scientific Bulletin of The Politehnica University of Timisoara. Romania.

[7] Dietzel F. 1996. Turbin, Pompa dan Kompressor. Edisi terjemahan. Jakarta Penerbit Erlangga.

[8] ESHA Part 2 2004. Guide on How to Develop a Small Hydropower Plant. Belgium.

[9] Khurmi R.S. 1977. A Text Book of Hydralic Machines. S Chand \& Company Ltd. New Delhi.

[10] Mockmore, C. \& Merryfield, Fred, The Banki Water Turbine, Journal www.Banki Water Turbin.com

[11] Zhen, H.S., Cheung, C.S., Leung, C.W., Choy, Y.S., "Effect of Hydrogen Concentration on the Emission and Heat Transfer of a Premixed LPG-Hydrogen
Flame", Int. Journal of Hydrogen Energy, Vol.37, 2012, hal. 6097-6105.

[12] Robert. W. \& McDonald, Allan T, Introduction to Fluid Mechanic, John Willey \& Sons, Singapore

[10] Hudan G A. Studi Pembangunan PLTMH Sumberan Pacet Mojokerto. ITS Surabaya.

[11] Sadrul I dkk, 2002. Sistem Mikrohidro Berhead Rendah yang Tepat untuk Bangladesh. ICECE 2002 26-28 Desember. Dhaka Bangladesh. 